\title{
SINERGIA
}

REVISTA DO INSTITUTO DE CIÊNCIAS ECONÔMICAS, ADMINISTRATIVAS E CONTÁBEIS (ICEAC)

\section{COMPETÊNCIAS PROFISSIONAIS E ESTÁGIO EM DIREITO: UM ESTUDO DE CASO NA PROCURADORIA-REGIONAL DA UNIÃO EM RECIFE - PE}

\author{
RAISA RIO BRANCO \\ DIOGO HENRIQUE HELAL*
}

\begin{abstract}
RESUMO
O artigo analisa a formação de competências profissionais de estudantes do curso de Direito, vinculados ao programa de estágio da Procuradoria-Regional da União, em Recife - PE, segundo o modelo de Paiva e Melo (2008). A abordagem utilizada foi qualitativa, de caráter descritivo, tendo sido adotado o estudo de caso. Os sujeitos foram escolhidos pelo critério de acessibilidade, totalizando 12 pessoas. As competências mais importantes e reconhecidas no processo de formação, via estágio, foram as seguintes: cognitiva, funcional, comportamental e ética. No que tange à contribuição do programa de estágio no desenvolvimento de competências dos estudantes, houve um entendimento de que ele efetivamente contribui. Por outro lado, na visão dos entrevistados, as IES não apresentaram as contribuições que seriam esperadas. Percebeu-se, de certa forma, um ruído entre as atuações da entidade de classe e a percepção dos entrevistados sobre essas contribuições. Ao final, foram propostas ações para melhor configuração do programa de estágio e sugestões de estudos futuros.
\end{abstract}

Palavras-chave: Competências profissionais, Estágio, Direito.

\section{ABSTRACT}

The article analyzes the training of professional competences of law students, linked to the internship program of the Regional Attorney of the Union, in Recife - PE, according to the model of Paiva and Melo (2008). The approach used was qualitative, of a descriptive character, and the case study was adopted. The interviewees were chosen according to the accessibility criterion, totaling 12 people. The most important competences, and recognized in the training process, via the internship program, were the following: cognitive, functional, behavioral and ethical. Regarding the contribution of the internship program in the development of students' competences, there was an understanding that it effectively contributes. On the other hand, in the view of the interviewees, the HEls did not present the contributions that would be expected. In a sense, we perceived a noise between the performances of the class entity and the perception of the interviewees about these contributions. At the end, actions were proposed to better configure the internship program and suggestions for future studies.

Key words: Professional competences, Internship program, Law.

Recebido em: 25-04-2019 Aceito em: 02-01-2020

\section{INTRODUÇÃO}

De acordo com o Fórum Econômico Mundial (2016), quase metade do conteúdo ensinado no primeiro ano de um curso, com quatro anos de duração, poderá estar desatualizado quando os alunos se graduarem, isso devido ao constante avanço tecnológico. Semelhantemente, em média, até 2020, mais de um terço das habilidades desejadas para o desempenho das atividades ainda não têm sido levadas em consideração em formação e treinamentos atuais.

Sendo assim, cada vez mais, serão necessárias habilidades técnicas, sociais e analíticas. Nesse contexto, acredita-se que programas de estágio supervisionado possam assumir um papel importante, na medida em que atuem como elemento integrador entre as necessidades do mundo acadêmico e organizacional, ainda vistos como antagônicos.

Essa previsão já havia sido antecipada por Nascimento e Teodósio (2005) quando alertaram para a dificuldade de escolas de nível superior acompanharem a produção de conhecimento, face ao ritmo do desenvolvimento tecnológico. Assim, entende-se que um dos desafios da formação superior no Brasil reside na formação e no desenvolvimento de competências profissionais nos estudantes universitários.

A palavra competência, apesar de ser empregada em diversas situações e compreensões, ainda não

\footnotetext{
* Mestra em Gestão Empresarial, pelo Centro Universitário FBV - UNIFBV - Wyden. E-mail: raisario@gmail.com

"* Doutor em Ciências Humanas (UFMG). Professor Titular do Mestrado Profissional em Gestão Empresarial, do Centro Universitário FBV - UNIFBV - Wyden.
} 
possui um consenso (SANT'ANNA, 2008). Segundo Fleury e Fleury (2001), competência refere-se ao saber agir responsável e reconhecidamente, por meio de conhecimentos, recursos e habilidades, que agrega valores econômico (à organização) e social (ao indivíduo).

Murari e Helal (2009) destacam os diferentes níveis de abordagem da competência: 1 - individual/profissional; 2 - gerencial/funcional e 3 - organizacional. Quanto ao modo de transmissão, Sveiby (1998) afirma que pode se dar sob a forma de informação ou prática - experiência. Nesse primeiro caso, tem-se como responsáveis as instituições de educação; no segundo, o mercado de trabalho e as organizações.

Diante desse contexto, o presente estudo tem como objetivo analisar a formação de competências profissionais de estudantes do curso de Direito, vinculados ao programa de estágio da ProcuradoriaRegional da União, em Recife - PE, segundo o modelo de Paiva e Melo (2008).

De acordo com esse modelo, existem quatro atores sociais envolvidos no processo de formação de competências profissionais: o primeiro é o Estado; o segundo são as instituições de ensino (acessadas, neste estudo, via entrevistas com estudantes estagiários da PRU5, em Recife - PE); o terceiro são as instituições coletivas (aqui, a Ordem dos Advogados de Pernambuco - OAB-PE); e, finalmente, o quarto são as organizações, de maneira em geral (neste caso a própria PRU5, em Recife - PE).

São objetivos específicos do estudo: i) analisar documentos essencialmente referentes à estruturação do programa de estágio na PRU5, os ligados à previsão e definição de estágio em regulamentações do MEC para o curso de Direito, bem como em normativas da OAB sobre estágio; ii) analisar as compreensões dos diversos atores acerca da formação de competências profissionais de estudantes do curso de Direito, vinculados ao programa de estágio da Procuradoria-Regional da União, em Recife - PE; e iii) comparar as compreensões dos diversos atores acerca do fenômeno estudado.

\section{COMPETÊNCIAS}

O interesse pelo estudo sobre competências surgiu como consequência da necessidade de reestruturação do sistema produtivo, até então dominante: o modelo fordista/taylorista de organização do trabalho, no qual predominava a noção de qualificação.

$\mathrm{Na}$ visão de Manfredi (1999), a qualificação diz respeito aos aspectos ligados ao posto de trabalho e não ao trabalhador e suas características: nessa perspectiva, o que importa é garantir que esse último seja preparado para desempenhar tarefas ou funções específicas e operacionais. Aqui, a ênfase é dada aos aspectos técnico-operacionais.

Para Helal e Rocha (2008), a qualificação e a competência são distintas, pois se apresentam para realidades díspares, ou seja, se expressam em contextos diferentes. Antes, para o sucesso da produção em massa, típica do modelo fordista de produção, exigia-se do trabalhador muita especialização.

No entanto, em decorrência das novas tecnologias empregadas nas atividades produtivas, típicas dos modelos flexíveis de produção, são exigidos do trabalhador, cada vez mais, atributos de ordem subjetiva (HIRATA, 1996; MANFREDI, 1999; LE BOTERF, 2003; HELAL; ROCHA, 2008).

Sendo assim, é corroborada a ideia de que a qualificação está ligada a aspectos técnicos, a uma realidade engessada e que a competência está relacionada a uma realidade complexa, flexível. Percebe-se que houve uma atualização conceitual do termo qualificação para que ela abrangesse os novos elementos ligados às capacidades que os profissionais do final do século XX e início do XXI precisam deter, ao que chamamos de competência. Aspectos subjetivos começam a fazer parte desse novo perfil profissional demandado.

Sant'Anna (2008) ressalta que a ideia de competência não é recente. Para o autor, apenas houve uma (re-) conceituação e (re-) valorização decorrente de vários fatores, entre eles, o processo de reestruturação produtiva. Segundo Manfredi (1999), a competência é um conceito que pode assumir diferentes definições e está em construção/reconstrução permanentemente.

Para Fleury e Fleury (2008, p. 30), a competência pode ser definida como "um saber agir responsável e reconhecido, que implica mobilizar, integrar, transferir conhecimentos, recursos e habilidades, que agreguem valor econômico à organização e valor social ao indivíduo".

A competência pode ser compreendida a partir de diferentes níveis: 1 - nível da pessoa; 2 - nível das organizações; 3 - nível dos países (FLEURY; FLEURY, 2001). O foco do presente estudo se dá no nível da pessoa, definida como a competência do indivíduo.

Para fins do presente estudo, foi adotado o conceito de Paiva e Melo (2008, p.349) para competência profissional, que será aprofundado mais adiante, quando da apresentação do modelo teórico:

[...] mobilização de forma particular pelo profissional na sua ação produtiva de um conjunto de saberes de naturezas diferenciadas (que formam as competências intelectual, técnico-funcionais, comportamentais, éticas e políticas) de maneira a gerar resultados reconhecidos individual (pessoal), coletiva (profissional), econômica (organização) e socialmente (sociedade). Concebe-se, então, competência profissional como a meta-reunião de maneira singular e produtiva de competências compostas por saberes variados. 
O debate acerca da competência também envolve a questão do seu caráter contextual. A competência só existe quando comunicada e permutada; ela não se reduz a um único indivíduo, depende da sua rede profissional; ela é, simultaneamente, individual e social, não sendo possível, assim, existir sem interação. Além da rede de relacionamentos, as máquinas, os meios de trabalho e os equipamentos, por exemplo, são recursos a serem mobilizados na construção da competência do indivíduo. A competência é, neste sentido, a capacidade de reunir saberes heterogêneos e diversos para a realização de uma dada tarefa (LE BOTERF, 2003).

Um dado curioso é apresentado acerca da competência: para que um indivíduo possa ser considerado competente em seu ambiente de trabalho, é preciso tempo. Isso porque ela pode variar de acordo com a situação em que intercede, depende de conjunto de imposições e de recursos. Ser competente não se resume a possuir capacidades ou saberes, o indivíduo pode deter esses conhecimentos e não saber aplicá-los oportunamente.

A competência só existe em uma situação concreta: surge quando há a união de um saber e um contexto. É importante destacar que a capacidade de resolver um problema não pode ser a única definição do termo, uma vez que existem problemas que não podem ser resolvidos, a exemplo de doenças cuja cura inexiste (LE BOTERF, 2003).

Sendo assim, percebe-se que o conceito de competência envolve uma multiplicidade de aspectos e questões. Diversos entendimentos e perspectivas têm sido discutidos; é tudo uma questão de ponto de vista, o que só enriquece o debate acerca do tema. O termo competência tem sido definido de diferentes formas, tornando-se um desafio adotar um único conceito que abranja toda a sua complexidade. Por essa razão, destaca-se a existência de duas correntes teóricas que serão abordadas nos tópicos a seguir.

\subsection{Perspectiva estadunidense sobre competência}

Dutra, Hipólito e Silva (2000) destacam a dificuldade quanto à conceituação de competência e a multiplicidade de interpretações que o termo possui. Sendo assim, o debate acerca da definição gira em torno de duas perspectivas teóricas: 1 - a estadunidense e 2 - a francesa.

Fleury e Fleury (2001) destacam o pioneirismo do trabalho de McClelland no debate acerca de competência. Para eles, a publicação do artigo "Testing for Competence rather than Intelligence", em 1973, inicia as discussões entre diversos estudiosos nos Estados Unidos.

A importância do trabalho de McClelland (1973) se dá, principalmente, pelo fato de questionar a validade dos testes de inteligência aplicados na sociedade americana da época, como forma de determinar a valoração de uma pessoa em detrimento de outra em ambientes acadêmicos e profissionais.

McClelland (1973) questionava o senso comum que acreditava que o desempenho escolar era determinante para um bom desempenho na vida profissional; para ele, os testes de inteligência da época não mediam a competência do indivíduo. A partir de uma pesquisa, o autor pôde constatar que melhores notas (desempenho acadêmico) não significavam melhor carreira profissional.

Autores como Boyatzis, Dailey, McClelland, e Spencer e Spencer são considerados os principais no estudo da literatura estadunidense acerca de competência. Nessa visão, competência "significa o conjunto de qualificações que a pessoa tem para executar um trabalho com nível superior de desempenho." (DUTRA; HIPÓLITO; SILVA, 2000, p. 162). Ainda de acordo com a visão estadunidense:

[...] competência é o conjunto de qualificações ou características preconizáveis, que permitem a alguma pessoa ter desempenho superior em certo trabalho ou situação. A competência pode ser prevista ou estruturada, de modo que se estabeleça um conjunto qualificador ideal, para que a pessoa apresente uma realização superior em seu trabalho. (DUTRA; HIPÓLITO; SILVA, 2000, p. 162-163).

Fleury e Fleury (2008, p. 28), contudo, criticam o modelo norte-americano: "em outras palavras, definir um estoque de recursos individuais necessários ao bom desempenho em cada cargo ou posição não é condição suficiente para atender a demanda por inovação e flexibilidade que se coloca às empresas".

Outra crítica feita à perspectiva estadunidense é a pouca diferenciação entre a definição de qualificação e a de competência. Cumpre notar que, nesta perspectiva, competência é entendida como um conjunto de qualificações, o que não resulta em um conceito eminentemente distinto.

\subsection{Perspectiva francesa sobre competência}

Contemporaneamente ao debate norte-americano acerca do conceito de competência, surge, também, a visão francesa. É no contexto de grandes mudanças econômicas, sociais e do acirramento da competitividade das empresas francesas que a discussão do conceito de competência se intensifica.

De acordo com Dutra, Hipólito e Silva (2000, p. 163):

Durante os anos 80 e 90, muitos autores contestaram essa definição de competência, associando-a às realizações das pessoas, àquilo que elas proveem, produzem ou entregam. De conformidade com esses autores, o fato de a pessoa deter as qualificações necessárias para certo trabalho não assegura que ela irá 
entregar o que lhe é demandado. Esta linha é defendida por autores como Jacques (1990), LeBortef (1995), Zarifian (1996), entre outros, em sua maioria europeus.

Dois grandes estudiosos se destacam nessa abordagem: Guy Le Boterf e Philippe Zarifian. De acordo com Le Boterf (2003, p. 12), "as competências geralmente são reconhecidas por meio de saber (conhecimento), saber-fazer (habilidades) e saber ser (atitudes)"

Tendo em vista que a competência é um agir responsável e reconhecido pelos outros, Le Boterf (2003) afirma que a competência é situada em 3 eixos: a) na própria pessoa; b) na sua formação educacional; e c) na experiência profissional.

A competência é realmente a competência de um indivíduo (e não a qualificação de um emprego) e se manifesta e é avaliada quando de sua utilização em situação profissional (na relação prática do indivíduo com a situação profissional, logo, a maneira como ele enfrenta essa situação está no âmago da competência) (ZARIFIAN, 2001, p. 67).

Conforme já abordado anteriormente, na visão de Zarifian (2001), a emergência do modelo de competência se dá em um contexto de evolução da concepção do trabalho e dos diversos elementos que o envolvem. A competência só se faz presente com as ações, ou seja, na prática, somente assim é possível perceber a sua existência (ZARIFIAN, 2001).

\subsection{Competência profissional, segundo Paiva e Melo (2008)}

O modelo teórico-conceitual adotado nesta pesquisa é o de Paiva e Melo (2008). É um modelo originado do estudo de Paiva (2007), que, por sua vez, foi inspirado no modelo de competência profissional de Cheetham e Chivers (1998). Esse último permite saber como a competência profissional e seus vários componentes são adquiridos e possibilita saber como os programas formais de desenvolvimento auxiliam ou inibem nesse processo (CHEETHAM; CHIVERS, 1998).

A escolha pelo modelo de Paiva e Melo (2008) se deu por duas razões principais: i) o modelo trata especificamente de competências profissionais, objeto de interesse deste artigo, e ii) traz vários atores no processo de desenvolvimento destas competências.

De acordo com Cheetham e Chivers (1998), a competência profissional é composta por quatro competências distintas, a saber:

1. competência cognitiva / conhecimento - competência técnica / teórica / especialista (conhecimento formal base de profissão); conhecimento tácito / prático (dificuldade de articular ou passar, sempre ligado com a performance de funções particulares); conhecimento procedural (rotinas básicas - como, o quê, quem, quando etc.); conhecimento contextual (organização, setor, geografia, base de clientes etc.); e aplicação de conhecimento (habilidades de síntese, transferência e conceitualização);

2. competência funcional - específica da ocupação (conjunto de funções específicas da profissão); processual / organizacional / administrativa (planejamento, monitoramento, implementação, delegação, evolução, administração do próprio tempo etc.); mental (capacidade de ler / escrever, de operar com números, de diagnosticar, habilidades em tecnologia de informação etc.); e física (coordenação, destreza manual, habilidades de digitação etc.);

3. competência comportamental ou pessoal - social / vocacional (autoconfiança, persistência, controle emocional e de estresse, habilidades de escuta e interpessoais, empatia, foco em tarefa etc.); e intraprofissional (coletividade, conformidade com normas de comportamento profissional etc.);

4. competência ética / valores: pessoal (aderência a lei e aos códigos morais ou religiosos, sensibilidade para necessidades e valores de terceiros etc.); e profissional (adoção de atitudes apropriadas, adesão a códigos profissionais de conduta, auto regulação, sensibilidade ambiental, foco em cliente, julgamento ético, reconhecimento dos limites da própria competência, dever em manter-se atualizado e em ajudar no desenvolvimento de neófitos na profissão, julgamentos sobre os colegas etc.).

Ainda de acordo com o modelo, permeando as quatro competências, haveria a metacompetência, caracterizada como "competências que estão além de outras competências" (CHEETHAM; CHIVERS, 1998, p. 274), que possibilitam ao indivíduo avaliar outras competências que detenha e/ou desenvolva.

A meta competência envolve aspectos como comunicação, criatividade, resolução de problemas, aprendizagem / autodesenvolvimento, agilidade mental, análise, reflexão.

Acreditando que o ambiente também pode influenciar a atuação do profissional, Paiva $(2007$, p. 46$)$ acrescentou ao modelo a competência política, definindo-a como a percepção e habilidade acerca dos jogos políticos inerentes às organizações, e associando-a às ações voltadas para o domínio nas fontes estruturais e normativas de poder na organização.

O modelo de Paiva e Melo (2008) possui dupla finalidade: identificar as competências individuais e compreender as relações entre os atores que atuam no processo de desenvolvimentos de competências individuais. 
Nesse modelo, 4 atores sociais atuam no processo de formação de competências profissionais: 1 Instituições de Ensino; 2 - Estado; 3 - Instituições Coletivas e 4 - Organizações. No centro desse modelo, localiza-se a competência profissional, formada por 5 diferentes tipos de competências: a) competência intelectual; b) técnico-funcional; c) comportamental; d) ética e e) política, as quais abarcam conjuntos de habilidades em cada uma delas. Ele pode ser visualizado na seguinte Figura 01:

Figura 1 - Modelo teórico de pesquisa

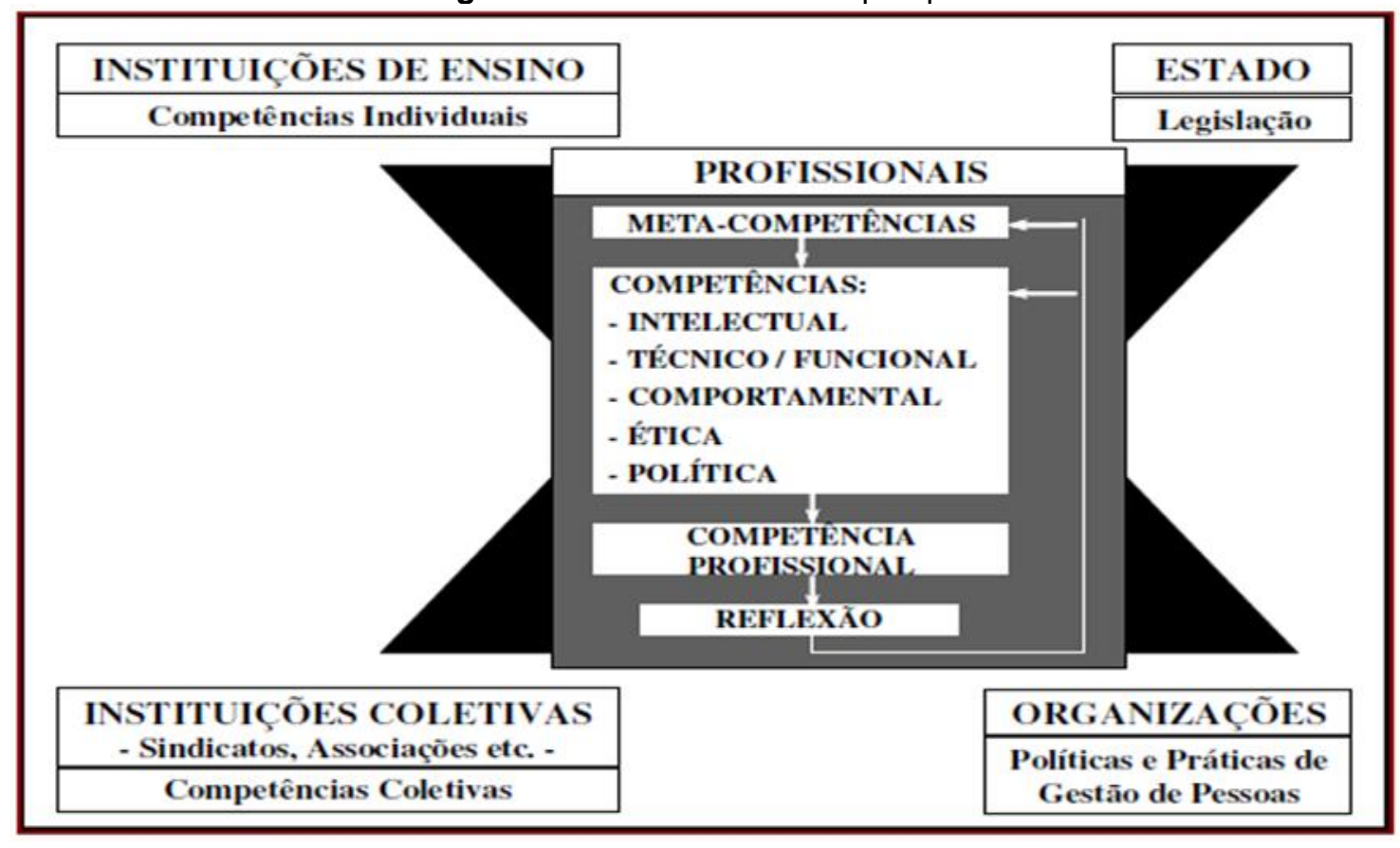

Fonte: PAIVA; MELO, 2008, p. 322.

A maneira como cada ator atua pode ser definida conforme descrição abaixo:

a. As instituições de ensino são formadoras formais do profissional, com suas políticas e práticas internas pedagógicas, responsáveis pela formação e desenvolvimento das competências profissionais individuais; b. O Estado, responsável por legislar e regular a formação superior; c. As organizações onde os profissionais trabalham, que, por meio de suas políticas e práticas de gestão, contribuem para a formação contínua e contextualizada do profissional; $d$. As instituições de interesse coletivo (associações e conselhos profissionais, sindicatos etc.), que regulam a atuação do profissional, bem como os sindicatos das categorias profissionais envolvidas, responsáveis pela defesa de interesse da categoria profissional. (PAIVA E SANTOS-JUNIOR, 2012, p. 901) abaixo:

Os elementos da competência profissional podem ser resumidos de acordo com o seguinte quadro

Quadro 1 - Componentes da competência profissional

\begin{tabular}{|c|c|}
\hline Componentes da competência profissional & Saberes característicos \\
\hline Cognitivo & $\begin{array}{c}\text { saberes teóricos, qualificações para o } \\
\text { trabalho }\end{array}$ \\
\hline Funcional & saberes aplicados, de realização de tarefas \\
\hline Comportamental & saberes pessoais e relacionais \\
\hline Ética & saberes axiológicos \\
\hline Política & saberes político-relacionais \\
\hline Fonte: Adaptado de Paiva e Melo $(2008,2009)$ e de Paiva et al. (2012, p. 4)
\end{tabular}

Diversos estudos no Brasil usaram o modelo de Paiva e Melo (2008) para analisar a formação e o desenvolvimento de competências profissionais. Melo (2012) buscou identificar que competências profissionais um docente de pós-graduação em ensino à distância on line, na opinião de professores e coordenadores, deveria possuir para lecionar administração.

Constatou-se que a maioria das competências profissionais desse professor se relacionava com o modelo proposto por Paiva e Melo (2008), com a predominância da competência cognitiva, seguida pelas competências funcional e comportamental e, em menor grau, a ética e a política. 
Barros, Melo e Agostini (2014), em outro estudo, analisaram a configuração e a gestão das competências profissionais de médicos de uma determinada unidade hospitalar mineira. Os resultados deste estudo indicaram a predominância das competências comportamentais, funcionais e cognitiva; e, em menor intensidade, a ética e a política.

Rodrigues (2011), analisando as competências dos egressos de um programa de pós-graduação de uma Universidade Federal, verificou a predominância de competências técnico-funcionais e intelectuais.

Por fim, Valadão Júnior, Almeida e Medeiros (2014) buscaram analisar as competências desenvolvidas por egressos da empresa júnior de determinada Universidade Federal e compreender o impacto dessas competências no desenvolvimento de suas carreiras profissionais. Eles constataram que as competências comportamentais e técnico-funcionais eram preponderantes, com baixa construção das competências éticas e políticas.

De um modo geral, foi possível constatar que as competências mais frequentemente apresentadas entre os sujeitos foram as competências cognitivas, funcionais e comportamentais, e as menos presentes foram as competências ética e política.

\section{ESTÁGIO E ENSINO SUPERIOR}

O ensino superior é caracterizado como um ambiente que forma cidadãos para o exercício da vida econômica e social, e produz conhecimentos. No entanto, apesar de seu importante papel, ele apresenta uma série de deficiências como, por exemplo, o fracionamento da ciência e por distanciá-lo dos acontecimentos da realidade (MARINHO-ARAÚJO; ALMEIDA, 2017).

Alguns estudiosos (FREY; FREY, 2012; ROESCH, 2005) destacam ser recorrente a afirmação de estudantes indicando que os modelos ensinados em sala não têm aplicabilidade prática. Os recémformados relatam não se sentir seguros para atuar profissionalmente, por não terem lidado com situações do mundo real ou por não terem lidado com documentos atinentes à profissão (FREY; FREY, 2012).

Para Francisco e Santos (2005), a competência, o conhecimento e a informação assumem, no cenário educacional do século XXI, um papel de destaque para as empresas, futuros profissionais e IES. No entanto, o que se percebe ainda é a deficiência por parte das IES em concretizar essa realidade no contexto educacional.

Diversos autores (BECKHAUSER et al., 2017; FREY; FREY, 2002; ROESCH, 2005) afirmam que o estágio é um importante meio de o aluno desenvolver competências profissionais e se aproximar do mundo empresarial.

Murari e Helal (2009) defendem que o estágio surge como elemento integrativo e essencial para que os estudantes preencham as possíveis lacunas existentes entre o meio acadêmico e o empresarial.

Para Lima e Carvalho (2000, p. 4), "o estágio se inclui em uma prática de ensino-aprendizagem com caráter pedagógico marcado pela relação professor-aluno em torno de uma experiência não acadêmica [...]".

Para Murari e Helal (2009, p. 268), ele "[...] deve ser analisado e compreendido como uma prática educativa que se desenvolve por meio de um fato social e perpetua no discente competências humanas, intelectuais e criativas, sendo um elo entre a práxis pedagógica e o mundo empresarial".

Ignácio e Barbosa (2016) discorrem que o estágio objetiva relacionar a prática com a teoria para que os acadêmicos possam desenvolver as habilidades imprescindíveis ao exercício da profissão. Esses mesmos autores acreditam que se trata de uma chance de o aluno praticar o que the foi ensinado em sala de aula, possibilitando o seu preparo para o mercado de trabalho.

Entre os benefícios da realização do estágio, Beckhauser et al. (2017) destacam a possibilidade de o estudante ter um melhor entendimento do que foi aprendido nas aulas, relacionando a teoria com a prática, melhorar a capacidade de criticidade e entender a realidade do mercado de trabalho.

Já na visão de Francisco e Santos (2005), entre os benefícios proporcionados pela prática do estágio, podem-se destacar: 1 - a questão de tratar-se de um meio diferenciado para adquirir conhecimentos e competências; 2 - a possibilidade de as empresas conhecerem as instituições de ensino e saberem se estas estão capacitando os estudantes de acordo com as necessidades daquelas; 3 - a permissão de as IES avaliarem a efetividade de seu ensino, podendo o estágio tornar-se, inclusive, uma referência para atualização curricular e 4 - condições de proporcionar aprendizado, também, para as organizações.

No que tange à graduação em Direito, a realização de estágio supervisionado é elemento curricular obrigatório. A Resolução CNE/CES n 9, de 29 de setembro de 2004, estabelece as diretrizes curriculares para o curso de graduação em Direito no Brasil. Nela, pode-se observar a presença obrigatória de 3 eixos de formação que devem compor o Projeto Pedagógico e Organização Curricular do referido curso, a saber: I) Eixo de Formação Fundamental; II) Eixo de Formação Profissional e III) Eixo de Formação Prática. O Eixo de Formação Prática, no qual o estágio supervisionado se insere tem como propósito proporcionar a interligação dos ensinamentos teóricos, desenvolvidos pelos outros dois eixos, com a prática.

Apesar de apresentar três eixos de formação, críticas são comuns quanto à forte ênfase dogmática no curso. Para Ignácio e Barbosa (2016), o ensino do Direito no Brasil privilegia aulas expositivas e não 
consegue acompanhar as necessidades que a sociedade do século XXI precisa. Pouco incentivo à pesquisa, seu caráter conservador, teórico e formalismo em excesso são apenas algumas das críticas apontadas ao Direito (IGNÁCIO; BARBOSA, 2016).

Além da possibilidade de estagiar conforme as diretrizes estabelecidas pela Lei de estágio (Lei $n^{\circ}$ 11.788, de 25 de setembro de 2008), abre-se a oportunidade ao graduando de Direito de realizar 0 estágio profissional de advocacia. Tal estágio, previsto pelo Estatuto da Advocacia e a OAB, Lei n 8.906, de 4 de julho de 1994, é intermediado pela OAB e tem duração de dois anos.

\section{METODOLOGIA}

A abordagem desta pesquisa foi essencialmente qualitativa e descritiva, tendo em vista a natureza do seu problema, o seu nível de aprofundamento e a expectativa por diferentes estratégias de investigação durante a coleta e análise dos dados (RAUPP; BEUREN, 2009; CRESWELL, 2010).

Caracterizou-se, ainda, como um estudo de caso, que se realizou na Procuradoria-Regional da União, em Recife - PE, órgão ligado a AGU - Advocacia-Geral da União, em Recife-PE. Esse método prevê uma investigação mais aprofundada e exaustiva, de maneira a permitir um conhecimento amplo e detalhado, acerca de um ou mais objetos (GIL, 2010).

Foram entrevistados 08 estagiários de Direito, na PRU5, tendo em vista o critério de saturação (GODOI; MATTOS, 2006). Além deles, foram entrevistadas as 2 gestoras do programa de estágio e 02 representantes da OAB-PE.

Denominaram-se os entrevistados da seguinte forma: a) E01 a E08, os estagiários de Direito; b) GES01 e GES02, as gestoras do programa; a primeira, com formação na área jurídica e a segunda em administração; c) OAB01 e OAB02, os representantes da OAB-PE; o primeiro, integrante da Comissão de Estágio e Exame de Ordem (CEEO) e o segundo, da Comissão de Educação Jurídica (CEJ).

Duas técnicas foram aplicadas para a coleta dos dados: pesquisa documental e entrevistas semiestruturadas. A primeira possibilitou um entendimento mais objetivo sobre a realidade do programa de estágio, na PRU5, bem como sobre a formação de competências profissionais dos estagiários. Por meio dessa técnica, objetivou-se analisar documentos essencialmente referentes à estruturação do programa de estágio, a saber: normativas internas, editais, provas discursivas, roteiro de seleção, relatórios de atividades do estágio e termo de compromisso de estágio. A partir da pesquisa documental, foi possível compreender a estruturação do programa e a melhor formulação das perguntas de entrevista.

A entrevista semiestruturada foi a adotada para o presente estudo. Ela pode ser definida como aquela que dispõe de um roteiro de perguntas ou assuntos, mas que, no decorrer das entrevistas, outras questões podem ser formuladas com a finalidade de melhor entender o tema em estudo (SAMPIERI; COLLADO; LUCIO, 2013). O roteiro das entrevistas foi elaborado a partir do modelo de Paiva e Melo (2008) e considerou a análise feita dos dados secundários desta pesquisa. As entrevistas ocorreram entre os meses de setembro e outubro de 2018.

Após a coleta, os dados foram analisados por meio da análise de conteúdo de Bardin (2011), definida como técnica de análise das comunicações. O modelo de análise de conteúdo proposto por Bardin (2011) é composto por três fases: 1) pré-análise; 2) exploração do material e 3) tratamento dos resultados, a inferência e a interpretação. Definida como a fase de organização, a pré-análise envolve, além de outros aspectos, a escolha dos documentos que serão analisados. Assim, no presente estudo, as entrevistas foram transcritas e, conforme estabelecido por Bardin, foi realizada a leitura "flutuante".

A seguir, as entrevistas transcritas foram recortadas, utilizando-se como a unidade de registro o tema. Tendo por base o modelo teórico-conceitual de Paiva e Melo (2008), estabeleceram-se as categorias a priori, a saber: metacompetências, competências cognitivas; funcionais; comportamentais; éticas e políticas.

Finalmente, a terceira e última fase, conhecida como tratamento dos resultados, a inferência e a interpretação, conforme previsto, as falas dos entrevistados foram tratadas e interpretadas de acordo com a finalidade dos objetivos estabelecidos.

\section{APRESENTAÇÃO E ANÁLISE DE DADOS}

No que diz respeito à média de idade dos estudantes entrevistados, todos eles estavam situados na faixa entre 20 a 25 anos. Quanto ao sexo, 5 eram mulheres $(62,5 \%)$ e 3 homens (37,5\%). Em relação à natureza da instituição de ensino ao qual estavam vinculados, 5 deles $(62,5 \%)$ estavam vinculados à instituição pública e o restante $(37,5 \%)$ à privada.

Quanto à periodização, grande parte deles (87,5\%) se encontrava já na metade e nos anos finais do curso; apenas 1 estudante $(12,5 \%)$ se encontrava nos anos iniciais, $4^{\circ}$ período. No que se refere ao tempo de casa, a maioria (62,5\%) possuía mais de 1 ano; 3 deles (37,5\%), entre 7 e 11 meses. Quando perguntados sobre se se tratava da $1^{\text {a }}$ experiência profissional, $62,5 \%$ responderam que sim; o restante, $37,5 \%$, que não. 
No que diz respeito aos representantes da OAB-PE, um deles (OAB01) estava vinculado à Comissão de Estágio e Exame de Ordem (CEEO), cuja competência abrange coordenação, fiscalização e execução de atividades correlatas ao estágio profissional de Direito. Quanto ao segundo representante (OAB02), ele estava vinculado à Comissão de Educação Jurídica (CEJ), cuja competência envolve a atuação de forma prévia sobre cursos jurídicos no que diz respeito às solicitações de criação, reconhecimento e credenciamento deles.

Quanto às gestoras do programa, uma tem a formação em administração, atuando como administradora, e a segunda tem formação jurídica, atuando como advogada na organização. A primeira é servidora do órgão desde 2007, atuando no programa desde 2012. A segunda é servidora desde 2005, atuando como gestora do programa desde 2017.

O Programa de estágio da Procuradoria-Regional da União em Recife (PRU5) envolve estudantes de nível médio e superior. O órgão dispõe de 48 vagas de estágio para estudantes de nível superior nas áreas de Direito, Administração e Ciências Contábeis; sendo que, dessa totalidade, 32 são restritas ao curso de Direito, área finalística do órgão.

Todos os anos realizam um concurso em nível nacional para admissão de novos estagiários. A forma de ingresso no programa de estágio se dá por meio de seleção pública, constituída de duas etapas: a primeira envolve a realização de provas objetivas e a segunda, entrevistas, com a possibilidade de aplicação de prova discursiva relacionada ao Direito. Exigem-se dos candidatos conhecimentos atinentes à Língua Portuguesa, a Direito Constitucional, Administrativo e Processual Civil. No último concurso, realizado em 2017, houve seleção apenas para estudantes da área de Direito, e foi possível a candidatura de graduandos que estivessem cursando a partir do 1 \% período.

O Programa não possui um desenho formal com a descrição de todas as atividades a serem desenvolvidas pelo estagiário de Direito, nem quais habilidades e competências o estudante terá desenvolvido após a conclusão do estágio, cabendo a cada supervisor, no caso em estudo, o advogado, o planejamento das atividades a serem desempenhadas pelos estudantes. Capacitações e treinamentos não são ofertados de forma regular e, quando o são, envolvem o desenvolvimento de competências estritamente técnicas.

O instrumento de avaliação do desempenho do estudante se dá por meio de um formulário padrão elaborado pelo agente de integração e é aplicado a cada 6 meses de efetiva vinculação do estudante ao programa de estágio. A possibilidade de contratação de agentes de integração é legalmente prevista para possibilitar um melhor andamento do instituto do estágio. Ao agente de integração, na organização em estudo, compete intermediar a relação entre os estudantes e a PRU5 no que diz respeito aos processos de recrutamento e admissão dos futuros estagiários.

Os estudantes de Direito, em regra, atuam sob a supervisão de um único advogado, a quem cabe toda a responsabilidade de formação desse estudante na organização. De acordo com a última seleção, realizada em 2017, não há previsibilidade das atividades que caberão aos estagiários, só disponibilizada essa informação na segunda etapa do processo seletivo. Conforme determinação da lei de estágio, a permanência do acadêmico no órgão deverá ter a duração máxima de até 4 semestres.

Todas as atividades desempenhadas pelos estudantes são aprendidas diretamente na realização das tarefas. Existe um processo prévio de ambientação do estagiário junto à gestão do programa, com duração média de quatro horas, para que ele possa conhecer melhor a organização e receber algumas orientações. Percebe-se que os antigos estagiários se dispõem de forma voluntária a ajudar os novos estagiários no desenvolvimento das atividades jurídicas, mas nada que aconteça de forma obrigatória ou planejada.

No Termo de Compromisso de Estágio (TCE), estão previstas todas as atividades a serem desempenhadas pelos estudantes. No caso dos estagiários de Direito, geralmente, envolvem atividades de auxílio nas seguintes questões: a) realização de buscas em legislação, doutrina e jurisprudência; b) no controle e exame de processos e ações; na confecção de pareceres jurídicos, despachos e peças similares; entre outras atividades afins.

\subsection{Competências profissionais identificadas, de acordo com pesquisa documental}

Nessa etapa, foram analisados todos os documentos fornecidos pela gestão do programa. Alguns de caráter público, como os editais e orientações internas, entre outros; e os de caráter privado, a exemplo dos formulários de avaliação utilizados nas entrevistas de seleção e as provas discursivas. No último processo seletivo para estágio na PRU5, no ano de 2017, a escolha de estudantes se deu por meio de seleção pública em nível nacional, composta por duas etapas: a primeira tratava-se de prova objetiva e a segunda de uma entrevista, essa última com a possibilidade de aplicação de questão discursiva.

$\mathrm{Na}$ primeira etapa da seleção, foi exigido dos candidatos apenas o domínio de competências cognitivas, com a previsão de conhecimentos relacionados à Língua Portuguesa, a conhecimentos gerais e a noções de Direito Constitucional, Administrativo e Processual Civil. Na segunda etapa, nas entrevistas, 
foram avaliados 3 critérios: conhecimento sobre a instituição (cognitiva), expectativas sobre o estágio (comportamental) e conhecimentos específicos (cognitiva). Destaque-se que, até pouco tempo atrás, exigiase como critério de pontuação na entrevista apenas a experiência prévia (funcional).

A seleção é, também, composta por prova discursiva, em que dois critérios são avaliados: 1 - correção gramatical (funcional) e 2 - conhecimento específico (cognitiva). A prova discursiva na PRU5 é elaborada por um advogado da União. Nas duas últimas provas discursivas, foram demandados dos candidatos conhecimentos referentes ao novo Código de Processo Civil, o que caracteriza um certo direcionamento da organização para exigência e foco nas competências cognitivas.

As atividades a serem executadas pelos estagiários, previstas no plano de estágio, estão relacionadas ao auxílio no controle e acompanhamento dos processos e ações (funcional); pesquisa de legislação, doutrina e jurisprudência (funcional); apoio na elaboração de notas técnicas e documentais (funcional); acompanhamento dos advogados na área jurídica no atendimento e orientação (funcional), entre outras atividades.

Tendo como parâmetro o modelo teórico de Paiva e Melo (2008), percebe-se que, documentalmente, só estão previstas a realização de atividades que tenham como foco o desenvolvimento de competências funcionais. No entanto, isso não significa que outras competências não estejam sendo desenvolvidas, o que será melhor identificado na realização das entrevistas.

Existe um programa de ambientação para os novos estagiários com duração média de 4 horas para que os estudantes conheçam um pouco da organização e algumas regras básicas. Nesse momento, são apresentadas as estruturas da AGU e da PRU5. Alguns pontos são esclarecidos como, por exemplo, a duração do estágio, valor da bolsa, recesso e protocolos administrativos; orientações de comportamentos também fazem parte dessa ambientação. Esse pode ser definido como um dos únicos momentos em que estagiário tem contato com a gestão do programa para entender um pouco sobre a realidade organizacional. Não são previstos, contudo, durante o estágio, cursos de capacitação que promovam o desenvolvimento de competências para além das funcionais.

A cada semestre concluído, o estudante é avaliado por meio de um formulário padrão disponibilizado pelo agente de integração, documento denominado "Relatório de Atividades do Estágio". O formulário é dividido em duas partes: uma a ser preenchida pelo estagiário e uma pelo seu supervisor. Primeiro, o estudante é convidado a responder a perguntas fechadas sobre oito aspectos relacionados ao estágio, a saber: 1 - aquisição de novos conhecimentos e experiências decorrentes da realização do estágio; 2 adequação do ambiente de estágio; 3 - impacto do estágio em competências de cunho comportamental; 4 contribuição do estágio com o rendimento escolar; 5 - respeito à carga horária contratual; 6 acompanhamento por parte do supervisor na realização das atividades; 7 - respeito às atividades contratuais. No último ponto, há uma pergunta aberta para que o estudante possa deixar algum comentário adicional sobre a avaliação do estágio.

$\mathrm{Na}$ segunda parte do documento, o supervisor é quem realiza a avaliação do estudante. A primeira questão é composta por sete subitens e o estudante pode ser avaliado de forma: 1 - ótima; 2 - boa; 3 - regular ou 4 - ruim. Os aspectos avaliados são: 1 - facilidade de compreensão das instruções/informações (metacompetências); 2 - assiduidade (funcional / comportamental / ética); 3 - pontualidade (funcional / comportamental / ética); 4 - cooperação (pares / supervisor) (comportamental / ética); 5 - discrição com informações organizacionais (comportamental / ética / política); 6 - capacidade de iniciativa (funcional / comportamental); 7 - nível de conhecimento teórico (cognitiva).

$\mathrm{Na}$ segunda questão é perguntado, de ótimo a regular, sobre o desempenho do estudante na realização de suas atividades (funcional). Na terceira, pergunta-se se o estudante tem condições de realizar tarefas mais complexas (funcional). Na quarta, se há interesse na inclusão de novas atividades para o estudante e, na última questão, se há interesse em realizar alguma observação adicional.

Percebe-se que há o predomínio de critérios de avaliação relacionados às competências funcionais, comportamentais e éticas. No entanto, no programa, não há previsão do desenvolvimento nem ações específicas que promovam essas duas últimas competências, cabendo ao estudante essa responsabilidade de desenvolvê-las, já que ele é avaliado e essas competências exercem um peso grande na sua avaliação.

\subsection{Perfil profissional, estagiário competente e profissional competente}

Oficialmente, não há um documento que estabeleça qual o perfil do profissional de Direito nem que competências profissionais ele deve possuir ou desenvolver. Também foram pesquisados artigos que, de alguma forma, apresentassem o perfil e competências, sendo localizado apenas um estudo, o que impossibilitou a generalização de informações. Essa mesma dificuldade já havia sido relatada por Rêgo e Isidro-Filho (2013) em sua pesquisa sobre o mapeamento de competências de advogados. Existe o Código de Ética e Disciplina da $\mathrm{OAB}$, mas que dispõe, majoritariamente, sobre questões de caráter comportamental e ético.

Sendo assim, considerou-se como referência desse perfil e de competências profissionais as estabelecidas nas Diretrizes Curriculares Nacionais do curso de graduação em questão, regulamentada 
pela Resolução CNE/CES № 9, de 29 de setembro de 2014, e as situadas na Portaria ํㅜ 443, de 30 de maio de 2018, que estabelece o perfil do graduando em Direito para fins de avaliação na prova do Exame Nacional de Desempenho dos Estudantes (ENADE) do ano de 2018.

O Estado, por meio da Portaria ํㅜ 443, estabeleceu 5 categorias que incluem aspectos pertencentes ao perfil do graduado em Direito: I. generalista, humanístico e axiológico na atuação do Direito; II. reflexivo e crítico para a adequada argumentação e interpretação dos fenômenos jurídicos e sociais; III. propositivo na elaboração de alternativas voltadas para a intervenção nas situações jurídico-sociais; IV. ético no exercício do Direito e na promoção do desenvolvimento da cidadania; e V. autônomo e dinâmico na condução de sua própria aprendizagem.

Tendo por referência esse documento, buscou-se fazer uma análise comparativa com base nas respostas dos entrevistados. Observou-se que ser um generalista, assim como disposto na Portaria no 443, foi uma característica também observada por dois estagiários (E01 e E04) e por um dos representantes da OAB (OAB02). Este último destacou a importância de esse profissional ser multifacetado.

O terceiro ponto apresentado pela Portaria, ser propositivo na elaboração de alternativas voltadas para a intervenção nas situações jurídico-sociais, foi destacado somente por dois estagiários (E07 e E08). Um deles ressalta o aspecto prático trazido pela abordagem francesa sobre o conceito de competência: [...] que saiba resolver problemas, né, um resolvedor de problemas [...] (E08).

Assim como a segunda característica apresentada pela Portaria, a quarta também não foi abordada por nenhum dos entrevistados. O último ponto estabelecido nesse documento foi observado e trazido por todos os grupos de entrevistados. Todos eles destacaram a importância de esse profissional ser uma pessoa atualizada, sempre em busca de novos conhecimentos.

A flexibilidade foi uma característica apontada por três estagiários (E01, E04, E07) e por um representante da Ordem (OAB02).

Ser um profissional moderno no sentido de ser aberto às novidades, de não possuir apego a formas antigas de pensar e agir, foi apontado pelos três grupos de entrevistados (estagiários, gestoras e OAB-PE).

Outro elemento presente nesse perfil, de acordo com quatro estudantes (E02, E04, E07, E08) e o OAB01, é a questão tecnológica. Para estes, o conhecimento e domínio de ferramentas ligadas à tecnologia no fazer do Direito, na atuação desse profissional, é de extrema relevância.

Capacidade de criar e manter networking foi uma característica tanto observada por uma das gestoras do programa (GES01) quanto por um dos representantes da OAB-PE (OAB02).

Sendo assim, na percepção dos entrevistados, e considerando a Portaria, o perfil do profissional de Direito do século XXI envolveria aspectos como: ser um profissional generalista, propositivo na elaboração de soluções, atualizado, flexível, moderno, conhecedor de tecnologia e interativo. De certa forma, preocupa a questão da ausência da indicação da dimensão ética na fala dos entrevistados, prevista apenas na redação da Portaria.

A seguir, questionou-se o que seria um profissional competente. As falas indicaram um predomínio das competências de ordem comportamental e ética (06 entrevistados cada), funcional (05 entrevistados) e cognitiva (04 entrevistados). As de menor ocorrência foram as relacionadas às competências políticas (02 entrevistados) e metacompetências (01 entrevistado).

Um dos estagiários trouxe a questão de não resumir a competência apenas como a capacidade de resolver problemas, corroborando com Le Boterf (2003), conforme relato a seguir:

Acho que é esse que consegue entregar valor ao cliente, né, seja um servidor público entregar valor à sociedade, seja um advogado privado entregar valor para o cliente dele, resolver o seu problema, e ainda que não consiga resolver com uma demanda sendo procedente, no caso de uma ação, mas entregar valor realmente, mostrar que deu o seu melhor, no caso, e conseguir, pelo menos, demonstrar para o cliente essa credibilidade, né. (E08)

Com relação ao componente comportamental, um estudante abordou a questão do saber trabalhar em meio à adversidade. Apesar de ter sido um ponto trazido por apenas um dos entrevistados, é uma questão extremamente presente na atuação no meio jurídico.

\subsection{A formação de competências profissionais}

Tendo por base o modelo teórico-conceitual de Paiva e Melo (2008), foi verificada a contribuição de cada um dos atores no processo de formação de competências profissionais dos estagiários, na percepção desses últimos.

Em primeiro lugar, eles foram questionados sobre a participação da própria organização (PRU5), por intermédio do programa de estágio, na formação de suas competências profissionais.

Ratificando as contribuições de Ignácio e Barbosa (2016) sobre a importância do estágio como um mecanismo de relacionar a teoria com a prática, três estudantes destacaram essa questão, como pode ser percebido no relato a seguir: 
quando eu entrei aqui, muita coisa começou a fazer sentido, né, porque, ah, eu fui lembrando: "ah, eu vi aquilo" que se aplicava dessa forma e tal e até para você, eu desenvolvi bem melhor, assim, a questão do entendimento lá do conteúdo que era repassado, é como eu digo, tudo começou a fazer sentido depois que você começa a estagiar [...] (E05).

No que tange às contribuições da PRU5, no desenvolvimento de competências dos estudantes, 04 estagiários responderam que a organização proporciona um ambiente no qual o estudante consegue desenvolver autonomia e flexibilidade.

A tabela 1, a seguir, indica as competências desenvolvidas pelos estudantes, segundo o relato dos estagiários, por meio do programa de estágio:

Tabela 1 - Competências desenvolvidas pelos estudantes por meio do programa de estágio

\begin{tabular}{lr}
\hline COMPETÊNCIAS & ESTAGIÁRIOS \\
\hline METACOMPETÊNCIAS/TRANSCOMPETÊNCIAS & E04 \\
\hline Autonomia & E04 \\
Autocrítica & E05 \\
Habilidade de comunicação & E06 \\
Agilidade & E01 \\
\hline COGNITIVA & \\
\hline Conhecimento contextual & E01, E02, E03, E05, E08 \\
\hline FUNCIONAL & E02, E06 \\
Habilidade de redigir & E05, E06, E07 \\
Habilidade de realizar pesquisas jurídicas & E07, E08 \\
Ser pontual & \\
Capacidade de lidar com processos & E02 \\
\hline COMPORTAMENTAL & E04 \\
\hline Relacionamento interpessoal (1) & E07 \\
Autoconfiança & - \\
Responsabilidade & - \\
\hline ÉTICA & \\
\hline POLÍTICA & \\
\hline R & \\
\hline
\end{tabular}

(1) Relacionamento interpessoal está relacionado simultaneamente às componentes comportamental, ética e política.

Fonte: dados da pesquisa

Conforme tabela 1 , as habilidades de maior ocorrência foram as relacionadas às competências de ordem funcional (07 entrevistados), às metacompetências e às competências comportamentais (03 estudantes cada). As de menor ocorrência foram as de ordem cognitiva, ética e política, com uma ocorrência cada.

Cabe ressaltar alguns pontos relativos às respostas dos estudantes. Um deles destacou que o estágio na PRU5 proporciona um melhor entendimento sobre os acontecimentos do mundo jurídico (conhecimento contextual), o que diz respeito à competência cognitiva.

A habilidade de redigir (funcional) foi destacada por mais da metade dos estagiários (E01, E02, E03, E05 e E08), sendo a de maior ocorrência. Essa habilidade foi destacada pelos estudantes no contexto da área jurídica.

Uma vez que os estagiários estão vinculados exclusivamente a um único profissional, o advogado, a quem cabe toda a formação e desenvolvimento do estudante, considerou-se imprescindível 0 questionamento sobre a atuação do supervisor, tendo em vista a responsabilidade que cabe a esse profissional. Todos os entrevistados elogiaram o desempenho do respectivo supervisor no desenvolvimento de suas atividades.

Após serem perguntados sobre as contribuições do estágio no desenvolvimento de competências, os estudantes foram questionados sobre a participação da IES nessa atividade. Apesar de os relatórios de estágio serem vistos como importantes e da necessidade de atuação da IES na supervisão e controle dessa atividade, conforme salientado por Almeida, Lagemann e Sousa (2006), quase a totalidade dos estudantes respondeu que esse acompanhamento por parte da IES só se dá por mera questão burocrática, ou seja, no preenchimento dos relatórios semestrais obrigatórios.

Responsáveis por regular a atuação profissional e manutenção de competências profissionais coletivas, as instituições de interesse coletivo se restringiram, no caso em estudo, à atuação da OAB-PE. Sendo assim, os estagiários foram provocados a responder sobre a atuação da Ordem na sua formação de competência profissional.

Dos estudantes de IES pública, nenhum deles percebe essa atuação, somente um deles (E07), 
estudante do 6 período, afirma que a OAB-PE esteve em sua faculdade uma única vez. Quanto aos de IES privada, somente um deles (E05) afirma que percebe essa atuação.

Importante indicar a percepção das gestoras da PRU5 quanto à contribuição do estágio na formação de competências profissionais. A gestora da área jurídica (GES01) afirmou que o estágio na PRU5 é diferenciado, permite ao estudante conhecer todas as fases do processo.

Sobre a atuação da organização na formação e desenvolvimento de competências do estagiário, a segunda gestora (GES02) apontou algumas dificuldades que o programa apresenta e que, na visão dela, impactam negativamente no andamento do programa, o que, consequentemente, pode vir a interferir no desenvolvimento de competências dos estudantes:

[...] a nossa bolsa de estágio, ela é a mesma há muito tempo, então, alguns estudantes terminam que preferem ir para outros estágios [...] por sermos órgão público também, a gente não tem, assim, autonomia pra dar todo o suporte que o estagiário precisaria, por exemplo, acontece de algumas vezes a gente não ter computador para todos os estagiários, né [...]

No que diz respeito às competências e habilidades desenvolvidas pelos estudantes junto ao programa de estágio, a GES01 destacou que a oportunidade possibilita ao estagiário o entendimento da abrangência do Direito e, principalmente, um conhecimento aplicado, diferentemente do que a Universidade proporciona.

Além do desenvolvimento de competências funcionais, a GES02 acredita que o programa proporciona ao estudante o desenvolvimento de competências de ordem comportamental e ética.

A GES02 encerra afirmando que o programa possibilita o desenvolvimento de habilidades relacionadas à pontualidade (funcional) e ao relacionamento interpessoal (comportamental, ética e política).

Por fim, buscou-se compreender o desenvolvimento de competências pelos estudantes, segundo o relato de representantes da OAB, por meio do programa de estágio. O representante OAB02 ressaltou a questão da oralidade (metacompetência), o olhar para o mercado (competência cognitiva), a capacidade de iniciativa (competência comportamental) e a resolução de problemas (metacompetências).

OAB01, por sua vez, destacou os benefícios dessa prática para ambos os envolvidos (estudanteorganização). Além disso, ele trouxe a questão de o estágio permitir a união entre teoria e prática.

Ainda no que se refere à contribuição na formação e desenvolvimento de competências dos graduandos de Direito, o representante OAB02 trouxe a atuação da Ordem nas IES que, consequentemente, impactam ou deveriam impactar nos discentes. Relatou ocorrência de reuniões com as IES, debates, trocas de "boas-práticas" entre as IES e afirma manter diálogos, com o objetivo de apoiá-las e orientá-las. Pelo que se observou, a influência da $O A B$ na formação e desenvolvimento de competências profissionais, por meio dos estágios, tem caráter muito mais institucional e normativo do que de relacionamento direto com os estudantes.

Em comparação aos outros estudos que se utilizaram do modelo teórico conceitual de Paiva e Melo (2008), percebem-se algumas similaridades com o presente estudo no que diz respeito ao desenvolvimento de competências. Os estagiários e gestoras foram demandados a responder sobre quais as contribuições do programa de estágio e houve semelhança e abrangência de respostas, principalmente, quanto aos aspectos funcionais e comportamentais.

$\mathrm{Na}$ maioria dos estudos, as competências de maior abrangência foram aquelas relacionadas as de ordem cognitiva, funcional e comportamental e as de menor foram aquelas de ordem ética e política. No presente estudo, além da baixa ocorrência de desenvolvimento das de ordem ética e política por parte do programa de estágio, percebeu-se, também, com relação às competências de ordem cognitiva.

\section{CONSIDERAÇÕES FINAIS}

Este artigo teve como objetivo geral analisar quais competências profissionais dos estudantes do curso de graduação em Direito, na Procuradoria-Regional da União, em Recife - PE, têm sido formadas por meio do programa de estágio, de acordo com o modelo teórico-conceitual de Paiva e Melo (2008).

Com base nas entrevistas, identificou-se que o perfil do profissional competente se relaciona às competências de ordem cognitiva, funcional, comportamental e ética.

Contudo, os resultados desta pesquisa indicaram que muitos dos estudantes não perceberam que a IES prepara para o mercado de trabalho. De acordo com as falas dos entrevistados, há uma baixa contribuição da IES no desenvolvimento de competências profissionais e no preparo para o mercado de trabalho. Isso é semelhante ao que ocorre em outros cursos, conforme indicam Zago, Souza e Bezerra (2007). Além disso, a baixa ocorrência do desenvolvimento de competências de ordem ética, política e, principalmente, cognitiva faz pensar sobre como o ensino deveria estar mais bem estruturado, com a finalidade de desenvolver melhor essas competências.

Sobre a atuação da OAB-PE, a maioria dos estagiários entrevistados e as gestoras do programa de 
estágio não a perceberam, e os que perceberam disseram que ela se dá de forma frágil. No entanto, de acordo com os relatos dos representantes da OAB-PE, existem ações concretas que têm sido realizadas. Acredita-se, assim, que pode estar ocorrendo algum ruído de comunicação entre os atores envolvidos.

Por fim, e apesar dos problemas levantados, é possível perceber várias contribuições do programa de estágio para com o desenvolvimento dos estudantes. Relacionamento da teoria com a prática, direcionamento de carreira e o contato efetivo com a atividade jurídica são algumas das contribuições apontadas pelos estagiários.

Não são previstas, por parte da gestão do programa, ações que proporcionem o desenvolvimento de forma continuada de outras competências para além das competências funcionais e que extrapolem a relação estagiário-supervisor.

Os resultados desta pesquisa indicam que há vários atores envolvidos no processo de formação e desenvolvimento de competências profissionais, mas que não há relacionamento entre eles neste processo. Nesse sentido, e considerando o modelo de Paiva e Melo (2008), cada ator acaba por enfatizar um ou alguns tipos de competência, em detrimento de outros, a partir de sua compreensão acerca da formação e desenvolvimento de competências profissionais por meio do estágio.

Mesmo diante da contribuição da PRU5 no desenvolvimento de competências dos estudantes, sugere-se maior atuação da gestão do programa com a promoção de atividades que desenvolvam competências para além daquelas diretamente relacionadas à atividade fim da organização, como, por exemplo, as relacionadas às de ordem comportamental, ética e política. Além disso, sugere-se que haja uma maior comunicação entre a gestão do programa e os supervisores de estágio, com a finalidade de alinhamento na formação dos estudantes, como também a criação de melhores instrumentos de avaliação desses estagiários.

\section{REFERÊNCIAS}

ALMEIDA, D.; LAGEMANN, L.; SOUSA, S. A Importância do Estágio Supervisionado para a Formação do Administrador. EnANPAD, 30., 2006, Anais... RJ: Anpad, 2006.

BARDIN, L. Análise de conteúdo. São Paulo: Edições 70, 2011.

BARROS, L.; MELO, T.; AGOSTINI, C. Competências profissionais e sua gestão: um estudo de caso com médicos. EnANPAD, 38., 2014. Anais... Rio de Janeiro: Anpad, 2014.

BECKHAUSER, S. et al. Orientação de estágio em administração: aproximando teoria e prática? Revista Brasileira de Ensino Superior, v. 3, n. 1, p. 56-77, ago. 2017.

BRASIL. Constituição Federal de 1988. Promulgada em 5 de outubro de 1988.

Lei $n^{\circ}$ 9.394, de 20 de dezembro de 1996. Estabelece as diretrizes e bases da educação nacional. Diário Oficial da União, Brasília, DF, 23 dez. 1996.

Ministério da Educação e Cultura. Resolução no 09/2004, de 29 de setembro de 2004. Institui as Diretrizes Curriculares Nacionais do Curso de graduação em direito e dá outras providências. Brasília: MEC, 2004.

Lei ํo 11.788 , de 25 de setembro de 2008. Dispõe sobre o estágio de estudantes e dá outras providências. Diário Oficial da União, Brasília, 26 de set. 2008.

Secretaria de Educação Superior. Edital de 1 de fevereiro de 2013. Diário Oficial da União, Brasília, DF, 1 fev. 2013. Seção 3, p. 55.

Ministério da Educação. Portaria no 443, de 30 de maio de 2018. Dispõe sobre o componente específico da área de Direito do Enade 2018. Diário Oficial da União, Brasília, DF, 04 jun. 2018. p. 30.

CHEETHAM, G.; CHIVERS, G. The reflective (and competent) Practioner: a model of professional competence which seeks to harmonise the reflective practioner and competence-based approaches. Journal of European Industrial Training, v. 22, n. 7, p. 267-276, 1998.

CRESWELL, J. Projeto de pesquisa. Porto Alegre: Artmed, 2010.

DUTRA, J.; HIPÓLITO, J.; SILVA, C. Gestão de pessoas por competências: o caso de uma empresa do setor de telecomunicações. Rev. adm. contemp., v. 4, n. 1, p. 161-172, 2000.

FLEURY, M.; FLEURY, A. Construindo o conceito de competência. Rev. adm. contemp., Curitiba, v. 5, n. spe, p. 183196, 2001.

Estratégias empresariais e formação de competências: um quebra cabeça caleidoscópio da indústria brasileira. 3.ed. São Paulo: Atlas, 2008.

FREY, M.; FREY, I. A contribuição do estágio supervisionado na formação do bacharel em ciências contábeis. Revista contabilidade vista e revista, v. 13, n. 1, p. 93-104, abr. 2002.

FRANCISCO, A.; SANTOS, N. Fatores críticos de sucesso na aquisição de competência no estágio curricular supervisionado: o caso dos cursos de engenharia do CEFET-PR. Revista Gestão Industrial, Curitiba: [s.n.], v. 1, n. 1, p. 26-36, jan/mar. 2005. 
GIL, Antônio Carlos. Como elaborar projetos de pesquisa. 5. ed. São Paulo: Atlas, 2010.

GODOI, C.; MATTOS, P. Entrevista qualitativa: instrumento de pesquisa e evento dialógico. In: GODOI, C.; BANDEIRADE-MELO, R.; SILVA, A. (orgs.). Pesquisa qualitativa em estudos organizacionais: paradigmas, estratégias e métodos. São Paulo: Saraiva, 2006.

HELAL, D; ROCHA, M. Da qualificação às competências: o que há de novo? E-Civitas, Belo Horizonte, v. 1, n. 1, p. 117, nov. 2008.

HIRATA, H. Da polarização das qualificações ao modelo da competência. In: FERRETTI, Celso João et al. Novas tecnologias, trabalho e educação: um debate multidisciplinar. Petrópolis: Vozes, 1996. p. 128-142.

IGNÁCIO, C.; BARBOSA, M. Estágio Supervisionado na Graduação em Direito. REDES - Revista Eletrônica Direito e Sociedade, v. 4, n. 2, p. 105-127, nov. 2016.

LE BOTERF, G. Desenvolvendo a competência dos profissionais. P. Alegre: Artmed, 2003.

LIMA, J.; CARVALHO, F. Estágio supervisionado em administração: confrontos e expectativas. EnEO - ANPAD, 1., 2000, Curitiba. Anais... Curitiba: ANPAD, 2000. p. 1-15.

MCCLELLAND, D. Testing for competence rather than for intelligence. American Psychologist, v. 28, n. 1, p. 1-14, 1973.

MANFREDI, S. Trabalho, qualificação e competência profissional - das dimensões conceituais e políticas. Educ. Soc., Campinas, v. 19, n. 64, p. 13-49, set. 1999.

MARINHO-ARAÚJO, C.; ALMEIDA, L. Abordagem de competências, desenvolvimento humano e educação superior. Psic.: Teor. e Pesq, v. 32, n. esp, p. 1-10, jan/mar. 2017.

MELO, R. Competências profissionais do professor do ensino superior para lecionar administração, pósgraduação lato sensu, na EAD on line: um estudo em IES da Região Metropolitana do Recife. 2012.181 f. Dissertação (Mestrado em Administração) - Programa de Pós-Graduação em Administração, Universidade Federal de Pernambuco, 2012.

MURARI, J.; HELAL, D. O estágio e a formação de competências profissionais em estudantes de administração. Gestão \& Planejamento, v. 10, n. 2, p. 262-280, jul/dez. 2009.

NASCIMENTO, L.; TEODÓSIO, A. O Estágio diante dos desafios do ensino em Administração: um estudo de caso sobre as percepções de alunos e supervisores. EnANPAD, 29., 2005, Brasília. Anais... Brasília: ANPAD, 2005.

PAIVA, K. Gestão de competência e a formação docente: um estudo em universidades no Estado de Minas Gerais. 2007. 278 f. Tese (Doutorado em Administração) - Faculdade de Ciências Econômicas da UFMG, Minas Gerais, 2007.

PAIVA, K.; MELO, M. Competências, Gestão de Competências e Profissões: perspectivas de pesquisas. Revista de Administração Contemporânea, v. 12, n. 2, p. 339-368, abr/jun. 2008.

PAIVA, K.; SANTOS, A.; DUTRA, M.; BARROS, V.; MULLERCHEM, K.; COSTA, R. Competências Profissionais (Ideais $x$ Reais) de Docentes de um Curso de Ciências Contábeis e sua Gestão: percepções de alunos e professores de uma instituição particular mineira. EnANPAD, 36., 2012, Rio de Janeiro. Anais... Rio de Janeiro: Anpad, 2012.

PAIVA, K.; SANTOS-JUNIOR, W. Competências profissionais de enfermeiros e sua gestão em um hospital particular. Rev Bras Enferm., v. 65, n. 6, p. 899-908, nov/dez. 2012.

RAUPP, F.; BEUREN, I. Metodologia da pesquisa aplicável às Ciências Sociais. In: BEUREN, Ilse Maria (Org.). Como elaborar trabalhos monográficos em contabilidade: teoria e prática. 3. ed. São Paulo: Atlas, 2006. cap. 3, p. 76-97.

RÊGO, M.; ISIDRO-FILHO, A. Mapeamento de Competências de Advogados. EnANPAD, 37., 2013. Anais... Rio de Janeiro: ANPAD, 2013.

RODRIGUES, H. Além do título de mestre: competências e aprendizagem no âmbito de um PPGA. 2011.183 f. Dissertação (Mestrado em Administração). Universidade Federal de Uberlândia, Minas Gerais, 2011.

ROESCH, S. Projetos de estágio e de pesquisa em administração. São Paulo: Atlas, 2005.

SAMPIERI, R.; COLLADO, C.; LUCIO; M. Metodologia de Pesquisa. PAlegre: Penso. 2013.

SANT'ANNA, A. O movimento em torno da competência sob uma perspectiva crítica. In: HELAL, D.; GARCIA, F.; HONORIO, L. (Orgs.). Gestão de Pessoas e Competência: teoria e pesquisa. Curitiba: Juruá, 2008. p. 239-253.

SVEIBY, K. A nova riqueza das organizações. Rio de Janeiro: Campus, 1998.

VALADÃO JÚNIOR, V.; ALMEIDA, R.; MEDEIROS, C. Empresa Júnior: espaço para construção de competências. Administração: Ensino e Pesquisa, Rio de Janeiro, v. 15, n. 4, p. 665-695, out/dez. 2014.

WORLD ECONOMIC FORUM. The Future of Jobs: Employment, Skills and Workforce Strategy for the Fourth Industrial Revolution. Geneva, jan, 2016. Disponível em: <http://www3.weforum.org/docs/WEF_Future_of_Jobs.pdf>. Acesso em: 31 jul. 2017.

ZAGO, C.; SOUZA, C.; BEZERRA, L. Competências Profissionais do Administrador: uma análise comparativa entre a necessidade do mercado e a formação dos administradores da Paraíba. Gestão.org. - Revista Eletrônica de Gestão Organizacional. vol. 5, n. 2, 2007.

ZARIFIAN, P. Objetivo Competência: por uma nova lógica. São Paulo: Atlas, 2001. 